2. Early diagnosis and treatment are important. 3. Three new cases are reported.

I would like to express my gratitude to Mr. B. J. Sanger and Mr. A. G. Dingley, the Consultant Surgeons under whose care these patients had been admitted, for permission to publish this report and for valuable advice and criticism.

\section{REFERENCES}

BOND, M. R., and RoBerTS, J. B. M. (1964): Intussusception in the Adult, Brit. J. Surg., 51, 818.
Burmeister, R. W. (1962): Intussusception in the $\frac{2}{3}$ Adult: An Elusive Cause of Recurrent Abdominal Pain, Amer. J. Dig. Dis., 7, 361.

RobB, W. A. T., and SouTER, W. (1962): Spontaneous $c$ Sloughing and Healing of Intussusception, Brit. J. $\overrightarrow{\vec{F}}$ Surg., 49, 542.

ROPER, A. (1956): Intussuscention in Adults, Surg. Gynec. Obstet., 103, 267.

Sanders, G. B., Hagan, W. H., and Kinnaird, D. W. (1958): Adult Intussusception and Carcinoma of ${ }^{\mathbb{\Phi}}$ the Colon, Ann. Surg., 147, 796.

Teasdale, D. H. (1953): Colo-colic Intussusception in the Adult, Brit. J. Surg., 41, 128.

\title{
A CASE OF MUNCHAUSEN'S SYNDROME PRESENTING AS RENAL COLIC
}

\author{
Roger SANDERS, B.M., B.Ch. \\ The Radcliffe Infirmary, Oxford.
}

Munchausen's syndrome is usually divided into three varieties; the abdominal, neurological and haemorrhagic types (Asher, 1951). The abdominal category classically presents with many abdominal incisions and a florid history.

Recently a case presented at the Radcliffe Infirmary who had but one incision, and described symptoms of a condition not previously associated with Munchausen's syndrome.

\section{Case Report}

A gloomy, solitary man of 42, M.T., presented at the Casualty Department, Radcliffe Infirmary, claiming that whilst driving his removal van through Oxford on a journey from Leicester to Bristol, he was doubled up with pain in his left loin, radiating down to his penis. The pain recurred at ten-minute intervals, and was associated with dysuria. On examination, he appeared tender over the left kidney. A tentative diagnosis of renal colic was made, and he was given pethidine, $100 \mathrm{mg}$. on 13 occasions. Emergency pyelogram, blood urea and midstream specimen of urine were all normal. After a week, the character and site of his pain changed, and he now appeared tender over the 12th dorsal vertebra. A "disc lesion" was suspected, and he was referred to an orthopaedic surgeon, who encased him in a plaster jacket. The following day, his pain was far more severe, and he appeared for once to be in real agony. It was decided to transfer him to an orthopaedic hospital and place him on traction.

As he seemed little distressed by the pain, which usually occurred when no doctors were present, a letter was sent to his local practitioner to find out more about his background, and he was seen by a psychiatrist, who was convinced that his story was genuine. However, on the day of his transfer, the situation was radically altered by the receipt from his practitioner of summaries received from no fewer than thirty hospitals which the patient had visited since the beginning of 1964. In total, he had had three cystoscopies, ten intravenous pyelograms, and fifteen straight abdominal $X$-rays, and twenty-one midstream specimens of urine had been examined. All were normal. When confronted later with this evidence by the psychiatrist, he became very angry, saying that no-one was going to call him a liar, and is alleged to have punched the psychiatrist on the nose, breaking his spectacles. Shortly afterwards, 은 he was admitted for psychiatric treatment under compulsory order.

From the summaries one can follow his course $\frac{\mathbb{T}}{\mathbb{Q}}$ round the Home Counties, starting in the larger hospitals in the centre of London, travelling around its periphery, then down to Hampshire and Dorse, and finally to Oxford. Like many other cases of $\vec{c}$ Munchausen's Syndrome (Galbraith, 1959), he wisedy chose to masquerade as a lorry driver, thus accounting for his distant home address. All the hospitio admissions, apart from the first, occurred in 1964, ard o it is possible to trace the way in which he has gradually learnt to perfect his story. On the first admission, he was merely labelled a hysteric; on ٌ the next, he had a normal appendix removed, and $\stackrel{\odot}{\triangle}$ for the subsequent three admissions his diagnosis was "abdominal pain, cause unknown". On each of the $\overrightarrow{\overrightarrow{0}}$ next 27 admissions, he successfully simulated renal 3 colic, and by the time he reached us, he was even passing bogus stones down the lavatory pan. As his perfected story fitted the classical concept of renal colic so perfectly, he gained easy admission. 흘 He never took his own discharge, and unlike other reported cases (Asher, 1951) showed few signs of the usual truculence. Perhaps aggression was allayed by frequent doses of pethidine.

Cases of Munchausen's Syndrome with symptoms such as M.T. manifested may escape detection; renal colic does not compel surgery so no mass of tell-tale abdominal scars need be $\rightarrow$ present. Although I have not found other reports of this type of renal Munchausen's Syndrome $N$ in the literature, one wonders if one should therefore deduce that it is uncommon.

I am indebted to Dr. E. D. Acheson for permission to publish this case and for his advice, and to Dr. J. Cooke, Earlshilton, Leicester, for letting me make use of the summaries.

\section{REFERENCES}

ASHER, R. (1951): Munchausen's Syndrome, Lancet, T i, 339 .

GaLbRAith, H. J. (1959): Munchausen's Syndrome, Brit. med. J., ii, 664 . 